\title{
DIAGNÓSTICO SOCIOECONÔMICO DA ÁREA DE PROTEÇÃO AMBIENTAL DA SERRA DE BATURITÉ - CEARÁ
}

\section{Socioeconomic diagnosis of the area of environmental protection of the Mountain of Baturité - Ceará}

\author{
Flávio Rodrigues do Nascimento ${ }^{1}$ \\ Marcos José Nogueira de Souza² \\ Maria Lúcia Brito da $\mathrm{Cruz}^{3}$
}

\section{RESUMO}

O presente trabalho mostra um diagnóstico socioeconômico de uma das Unidades de Conservação mais importantes do Ceará e do semiárido brasileiro - Área de Proteção Ambiental da Serra de Baturité. Esta protege legalmente ecossistema úmido no contexto regional de terras secas predominantes na região, sendo caracterizada como área de exceção ecológica. Tem histórico de ocupação relacionado a atividades agrícolas típicas de climas úmidos, com agentes produtores do território apresentando dinâmicas no tempo e no espaço relacionado às atividades exploradoras das potencialidades dos recursos naturais. O diagnóstico apresenta as principais questões sobre as gentes produtores do espaço urbano e rural na APA da Serra de Baturité, bem como detalhes sobre a estrutura etária e o panorama do mercado de trabalho.

Palavras-chave: Serra de Baturité; Unidade de Conservação; aspectos socioeconômicos.

\begin{abstract}
The present work shows a socioeconomic diagnosis of one of the Units of Conservation more important of Ceará and of the semi-arid Brazilian - Environmental Protection Area of the Serra of Baturité. This is because legally protect wetland ecosystem in the regional context of dry lands prevalent in the region, being characterized as an area of ecological exception. It has historical of occupation related to typical agricultural activities typical of humid climates, with agents producing of the territory presenting dynamics in time and space related space related to the exploiting activities of the potentialities of natural resources. The diagnosis presents the main subjects on the people producing of the urban and rural space in APA of the Serra of Baturité, as well as details on the age structure and the outlook of the job market.
\end{abstract}

Keywords: Serra de Baturité; Units of Conservation; socioeconomic aspects.

1 Geógrafo, doutor em Geografia, professor do departamento e do programa de pós-graduação em Geografia da UFF. E-mail: flaviogeo@bol.com.br.

2 Geógrafo, doutor em Geografia, professor do departamento e do programa de pós-graduação em Geografia da UECE. E-mail: mestgeo@uece.br.

3 Geógrafa, doutora em Geografia, professora do departamento e do programa de pós-graduação em Geografia da UECE. E-mail: mlbcruz@gmail.com. 
NASCIMENTO, F. R. et al. Diagnóstico socioeconômico da área de proteção ambiental...

\section{INTRODUÇÃO}

A Serra de Baturité constitui um dos mais importantes enclaves de mata úmida do Ceará. Representa um ambiente de exceção do bioma da caatinga e é o principal centro dispersor de drenagem que converge para a Região Metropolitana de Fortaleza (RMF). A sua proximidade de Fortaleza, da qual dista cerca de $80 \mathrm{~km}$, aliada aos atrativos naturais e culturais - clima ameno e com médias de temperatura de $20^{\circ} \mathrm{C}$, paisagens serranas que alternam vales fechados e abruptos do relevo, vegetação exuberante e sempre verde, águas correntes ou pequenas represas, pomares com variedade de lavouras - têm implicações positivas que motivam o adensamento demográfico e potencializam a pressão sobre a base dos recursos naturais. Tratam-se de fatos atrativos que têm contribuído historicamente para intensificar os processos de degradação, comprometendo a biodiversidade e o equilíbrio ambiental, recursos hídricos e descaracterizando a paisagem serrana.

O histórico de ocupação da Serra remonta ao Século XVII (1680) e tem relação direta com o processo de ocupação territorial portuguesa no Ceará. As particularidades deste processo derivam das demandas específicas de terras agricultáveis e de interesse de exploração de recursos naturais com potencialidades superiores aquelas encontradas no semiárido, que predomina no Ceará Estado como um todo.

Em termos de abrangência o enclave úmido da Serra de Baturité contempla integralmente as áreas dos municípios de Guaramiranga $\left(59 \mathrm{~km}^{2}\right)$, Pacoti (112 $\left.\mathrm{km}^{2}\right)$, Aratuba $\left(143 \mathrm{~km}^{2}\right)$ e Mulungu $\left(135 \mathrm{~km}^{2}\right)$, os quais serviram de referência para delimitação do Perímetro da Área de Proteção Ambiental da Serra de Baturité. Em rigor, esta Unidade de Conservação (UC) foi criada em 1990 pelo Diploma Legal № 20.956 e abrange uma área que corresponde a 32.690 ha. Abrange também parte dos Municípios de Baturité, Capistrano, Palmácia e Redenção (Figura 1).

Nada obstante, o objetivo deste artigo é mostrar os principais resultados do diagnóstico socioeconômico da APA em questão, para que sirva de base para elaboração de futuro planejo de manejo da mesma.

\section{HISTÓRICO DA OCUPAÇÃO}

O Ceará teve uma colonização considerada tardia. Alguns fatos concorrem para isto: a) suas praias arenosas constituíam-se como empecilho à exploração econômica, sobretudo no que se refere à agroindústria do açúcar. Além do mais, as correntes marítimas e ventos eram desfavoráveis às embarcações à vela, dificultando a expulsão dos holandeses instalados na região; b) outro aspecto revelava-se pela existência de índios ariscos muito pouco sociáveis a presença de alienígenas em seus territórios.

A ocupação portuguesa se deteve praticamente na ocupação da faixa litorânea entre 1611 e 1631 nas proximidades do Forte de São Sebastião, não se interessando pela hinterland cearense. $\mathrm{E}$ a fase da ocupação holandesa entre 1637 e 1654 não alterou essa configuração espacial. Tão somente, com a busca de terras destinadas à agropecuária pelos chamados "caminhos do gado", seguindo os vales dos principais rios - Jaguaribe e Acaraú -, demandando nesta marcha os sertões do Piauí, sob expulsão de indígenas. Neste sentido, IBAMA/UECE (2001, p. 8) explicam que:

\begin{abstract}
Não causa espanto que as áreas de exceção no interior do semi-árido pastoril, como a Serra da Ibiapaba, Serra do Baturité e Serra do Araripe, se tornassem últimos redutos de populações indígenas. Essas áreas, sobretudo no Maciço de Baturité, estavam fora das rotas e dos caminhos do gado cruzamentos que deram origem a muitas cidades do sertão do Ceará.
\end{abstract}

Neste contexto, o Diagnóstico e Macrozonemanento do Ceará (1998, p. 20), visualiza o povoamento estadual em cinco unidades civilizatórias, dentre as quais podem ser destacadas as serras úmidas. Quais sejam: os sertões; o litoral; o vale do Cariri; as serras úmidas; e Vales úmidos dos maiores rios.

O Maciço de Baturité, portanto, se enquadra no vetor de colonização e civilização das serras úmidas, a despeito de outras serras (Maranguape, Aratanha, Uruburetama, Uruoca e Ibiapaba), com características específicas que se assemelham ao Vale do Cariri, com modos de viver e de trabalhar reconhecíveis no contexto geral da civilização cearense, visto que permitem tipologias de ocupação e exploração do solo e de povoamento bem específicos.

De fato, a presença portuguesa no Maciço de Baturité ocorreu em 1680, quando a região foi alcançada pelo rio Choró através de Estevão Velho de Moura e mais seis rio-grandenses do norte, os quais ganharam do Capitão-mor Sebastião Sá, uma sesmaria com extensão de mais de três léguas compreendendo quase todo o curso do rio Choró a montante, alcançando grande parte da atual microrregião de Baturité. Sendo que em 1702, Marcelino Gomes recebeu a primeira sesmaria na área do Município de Redenção (Acarape, na Serra do Acará), começando no Poço Paracupeba (PDR, 2001, p. 5). 
NASCIMENTO, F. R. et al. Diagnóstico socioeconômico da área de proteção ambiental...

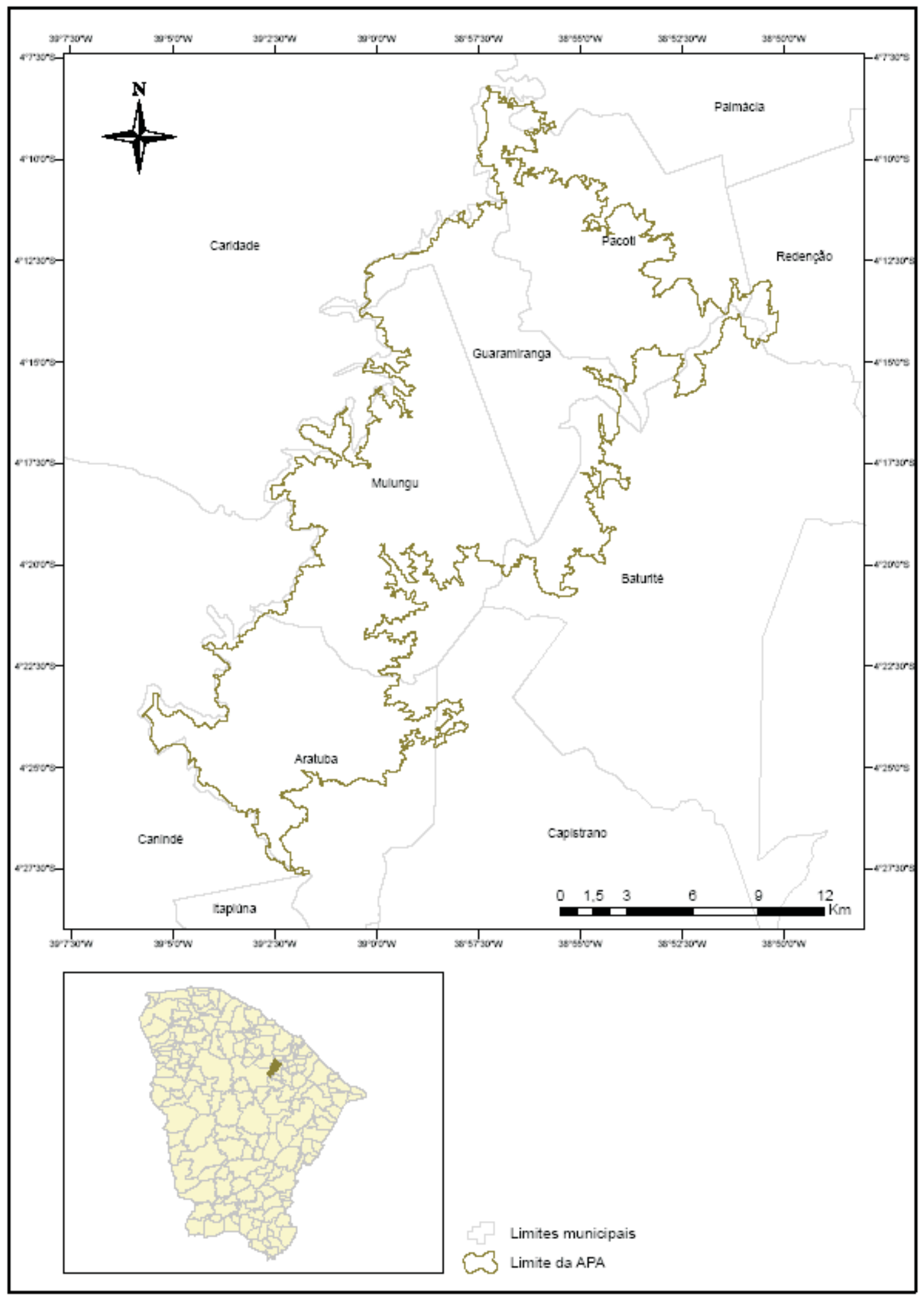

FIGURA 1 - APA DA SERRA DE BATURITÉ E SUA ÁREA DE INFLUÊNCIA

R. RA'E GA, Curitiba, n. 20, p. 19-33, 2010. Editora UFPR

21 
NASCIMENTO, F. R. et al. Diagnóstico socioeconômico da área de proteção ambiental...

Contudo, complementa o PDR (2001), as terras do Maciço continuaram sem ocupação efetiva até a segunda década do século XVIII (1718), quando o Ten. Coronel Manuel Duarte da Cruz ocupou parte da região, atualmente denominada Aracoiaba. Segundo Ceará (1991, p. 12), outras sesmarias concedidas na Serra de Baturité foram: do Pe. Filipe Pais Barreto, 1727; a de Tomás Galvão e mais seis companheiros, 1735; a de Manuel Rodrigues das Neves, 1735; a de Pedro da Rocha Maciel, 1736; e a de Teodósio de Pina e Silva. Deste modo, o território hoje ocupado pelas cidades que compõem o Maciço como um todo, foi ocupado originalmente a partir da concessão de semarias que abrangiam terras entre os vales do rio Choró e da Serra de Baturité no início do século XVIII até praticamente sua metade (1746). Sendo que a atividade principal de fixação do homem foi a agricultura, com ponto focal no engenho de cana-de-açúcar, tendo como paradigma na época, a Comarca de Baturité. Realmente, a cana-de-açúcar e o café foram as duas formas de atividades responsáveis pelo povoamento e formação dos núcleos urbanos nesses ambientes úmidos e de exceção no Ceará.

Muitas tribos resistiram à ocupação dos brancos até a segunda década do século XVIII, quando os índios remanescentes se refugiaram em destinos diversos, outros foram incorporados ao pastoreio nos sertões e muitos foram reunidos em pequenos aldeamentos constituídos por missionários. Tais aldeamentos originaram diversas cidades no Ceará, principalmente no Maciço de Baturité.

Porquanto, o topônimo de Baturité tem origem no Tupi: ybatr'etê. Significa: ybytira: serra morro + etê: serra por excelência, a grande serra. Conforme Ceará (2002, p. 21) entre as outras interpretações conhecidas sobre a origem do topônimo Baturité tem-se à expressão "baturieté", ou seja, "narceja (uma ave) ilustre" ou de "batuira" e "eté", que significa "valente nadador". Todavia, outra versão etimológica diz que o nome original do lugar não era Baturité e sim Batieté. Ratificando esta questão a história oral na fala popular de velhos habitantes do lugar, caboclos de origem indígena, pronunciavam Batieté. Em tupi, tem-se: bu (sair, rebentar, sair da fonte), ty (água) e eté (boa), que exprime "butieté" (sair água boa), em referência às inúmeras fontes de água de qualidade na área serrana do Maciço. Ademais, a denominação da região ao lume de sua construção simbólica, assistiu mutações ao longo do tempo, acompanhando o processo de ocupação. Sendo que em cada denominação a marca de uma forma específica de apropriação marca o território.

Com a investida para o semiárido, para expansão de terras destinadas a pecuária extensiva, notadamente demandando terras nos vales dos rios Jaguaribe e
Acaraú, é que terras interioranas do Ceará foram conquistas sob confronto com os indígenas. Pioneiramente, em 1740, os irmãos Arnáu, Sebastião e Cristóvão Holanda, juntamente com Manoel Ferreira da Silva, habitaram, em temporada, o Maciço. Os descendentes destes pioneiros foram responsáveis pela colonização de diversos setores do Maciço de Baturité, onde hoje estão instaladas diversas cidades, tais como Aratuba, Baturité, Guaramiranga, Mulungu e Pacoti.

Foram, assim, redefinindo os mecanismos de apropriação do território, com a criação de vilas funcionando com um instrumento para expandir o poder real. Para o Maciço de Baturité, cabe destacar que em 6 de agosto de 1763, foi então, criada a vila onde hoje se localiza Baturité. E em 31 de março de 1764 foi publicado o edital para a instalação da vila de Monte-Mor o Novo da América, no mesmo lugar da antiga Missão de Nossa Senhora da Conceição.

Foi em função das condições climatérias do Maciço com a produção de café, no século XVIII no ano de 1824, efetivamente a região entra no circuito mercantil de produção até o século XIX, que ao lado da cana-deaçucar tornaram-se os principais produtos agrícolas.

Para se ter uma ideia do que a cafeicultura representou Girão (1985), remetendo-se a Capistrano de Abreu, dastaca que:

No Ceará não é possível falar numa aristocracia do café, como a do Rio de Janeiro e de São Paulo. No entanto, merece destaque a pequena nobreza dos cafezais baturiteenses, de famílias ricas, com hábitos e costumes mais apurados e projeção social mais saliente. Os Linhares, os Caracas, os Holanda, os Ferreira Lima, os Queirós, os Sampaio, os Dutra, dos quais hão saído homens ilustres, são os representantes mais em alto daquela fidalguia serrana (GIRÃO, 1985, p. 167).

Para Ceará (2002, p. 19), as cidades que atualmente compõem o Maciço de Baturité, embora só tenha se consolidado no século XIX, têm suas origens que remontam ao século XVII. Incluem-se aí as primeiras habitações com diversos sítios urbanos, vilas e distritos, que ajudam a compor um dos mais celebres patrimônios culturais de tradições e de história do Ceará.

Mesmo após o período inicial de expansão da produção cafecultora, começaram a surgir estrangulamentos que levaram essa cultura à regressão. Quando a estrada de ferro alcançou a região produtora, a exiguidade de terras para expansão cafeeira contribui para o envelhecimento dos cafezais e a perda de produtividade em decorrência do empobrecimento e esgotamento dos solos.

Contudo, há de se destacar que além destes 
NASCIMENTO, F. R. et al. Diagnóstico socioeconômico da área de proteção ambiental...

problemas o café enfrentou obstáculos em relação à sua expansão, como o custo de transportes e vias de comunicação impactavam negativamente o lucro, reduzindo sua margem de segurança. Fato que aproxima o Maciço de Baturité ao contexto do semiárido, fornecido pela base sociotécnica. Destarte, tal base não promoveu o desenvolvimento de novos métodos, muito menos o aperfeiçoamento de equipamentos. Isto provocou carências e similar estagnação e pobreza em relação às demais partes do Estado, como, por exemplo, em relação ao semiárido.

Assim, pode-se afirmar que desde os primórdios da ocupação do território pelos colonizadores, a agricultura foi a atividade principal de fixação da população. Mas diferenciando-se do semiárido, onde a base econômica estava sustentada no gado e no algodão, o destaque em Baturité se deu com base na monocultura, mesmo que tenha sido buscado o favorecimento da diversidade natural da Serra para o plantio de outras atividades agrícolas. Assim é que na área serrana o café proliferou e nas planícies alveolares a cana-de-açúcar prosperou, enquanto culturas majoritárias ajudaram na formação da base de fixação e desenvolvimento de núcleos urbanos.

Esses trabalhos agrícolas ocorreram em razão das atividades de catequese pelas organizações religiosas fundamentais na organização de missões jesuíticas para constituição de aldeamentos indígenas, que serviram de base para o desenvolvimento do primeiro núcleo urbano da Serra. À exceção de Palmácia que foi desmembrada de Maranguape, foi aí que teve início a divisão espacial dos municípios componentes do Maciço, que sofreram reordenamentos territoriais a partir de desmembramentos do município de Baturité.

Já no século XX, o desenvolvimento econômico da região do Maciço teve início com:

[...] a Lei provincial $n^{\circ} 844$, de 9 de agosto de 1858, elevou antiga vila à categoria de cidade, com a denominação de Baturité. As alterações administrativas foram dando forma à atual estrutura e divisão administrativa municipal. Em 1868 ganha autonomia o município de Redenção, Em 1890, a região encontrava-se formada pelos Municípios de Baturité, Pacoti, Guaramiranga, Mulungu, Aratuba, Redenção e Aracoiaba (CEARÁ, 1991, p. 32).

A cidade de Baturité apresentou seu apogeu entre os anos de 1920 e 1930, na época que se transformou em centro educacional com a instalação de escolas religiosas, além de já se apresentar como centro regional cultural, de serviços e comércio. Com escolas religiosas (Jesuítas (1927), Salesianas, 1931 e 1932, e das Irmãs de Caridade), a cidade passou a receber alunos de praticamente todo o país (CEARÁ, 2002, p. 27).

Ainda na década de 1930, após a Revolução deste mesmo período, foi modificada a divisão territorial de Baturité (distritos de Baturité, Caio Prado; Candeia, Capistrano de Abreu e Itaúna), sendo omitidos Putiú, Guaramiranga, Pernambuquinho e Riachão.

Segundo Ceará (2002, p. 25), a partir dos anos de 1930, o arranjo político-administrativo de Baturité, principal município do Maciço de mesmo nome, apresentou os principais aspectos destacados em seguida. Em 1938, o Decreto-lei $n^{\circ} 448$, de 20 de dezembro, deu a Baturité parte do distrito de Pindoba, extinto e pertencente à Pacoti, sendo também anexado ao distrito da sede o território de Candeia. Em 1938, Baturité apresentava em sua configuração territorial os seguintes distritos: sede, Capistrano (ex-Capistrano de Abreu), Itaúna e Caio Prado. Cinco anos mais tarde, 1943, Itaúna teve seu nome modificado para Itapiúna.

Capistrano foi emancipado em 1951, quando foi desmembrado de Baturité. Seis anos depois foi criado o Município de Itapiúna, composto dos distritos de Itapiúna e Caio Prado, também desmembrados de Baturité, ficando, o município de Baturité reduzido ao do distrito-sede. Em 1957 Palmácia foi desmembrada de Maranguape. Os processos mais recentes datam da década de 80 . Sendo que atualmente a divisão administrativa da região está, assim, composta por treze municípios: Acarape, Barreira, Mulungu, Baturité, Guaramiranga, Capistrano, Ocara, Redenção, Pacoti, Palmácia, Itapiúna, Aracoiaba e Aratuba.

Quanto ao mais, as serras úmidas próximas de Fortaleza compartilham o destino do litoral, pois estão se transformando em região de veraneio, reduzindo os ex-produtores agrícolas em caseiros e vigias, que passam a sobreviver dos salários exógenos.

\section{AGENTES PRODUTORES DO ESPAÇO URBANO E RURAL NA APA DA SERRA DE BATURITÉ}

Os espaços urbano e rural que compõem a APA em apreço foram produzidos ao longo do tempo e de modo diferenciado conforme cada conjuntura econômica e ciclo produtivo sob a guisa de ocupação do território buscando ativos ambientais necessários a produtividade agrícola, como visto anteriormente.

Assim, quer seja no período da produção açucareira ou cafeeira, atividades de maior destaque na historiografia do Maciço, os agentes produtores do espaço regional foram ocupando, vis-à-vis, terrenos considerados pela lógica da produção mercantil como 
NASCIMENTO, F. R. et al. Diagnóstico socioeconômico da área de proteção ambiental...

sendo de interesse para o desenvolvimento de atividades produtivas, instalações de núcleos urbanos - localizados estrategicamente conforme as vias de acesso -, estabelecimento de propriedades rurais ou religiosas.

Desta feita, a coroa portuguesa, donatários de sesmarias, os jesuítas, os trabalhadores em geral - escravos ou não-, promoveram nos tempos de colonização modificações substanciais na paisagem, artificializando-as progressivamente à medida que iam incorporando terras. Atualmente, e de maneira específica, o território da APA do Maciço de Baturité é formado ou está contíguo a um conjunto de 7 cidades ou sedes municipais e 9 distritos, quais seja; sedes dos Municípios de Aratuba, Capistrano, Mulungu; e Sedes e distritos de Pacoti (Colina, Fátima e Santa Ana), Guaramiranga (Sede e Pernambuquinho), Baturité (sede, Boa Vista, São Sebastião), Palmácia (Sede, Gado e Gados dos Rodrigues) e Redenção (Guassi).

Tais cidades, núcleos urbanos e comunidades rurais, tiveram seu processo histórico e de crescimento muito vinculado à cidade de Baturité, em específico, e no geral, há toda uma lógica de acumulação mercantil entre os séculos XVII e XX que por si só provocam diversas negligências e estiolamentos ambientais, como já mencionado. Sendo que a dinâmica demográfica, os principais aspectos socioeconômicos, a conservação da natureza, bem como os problemas de uso e ocupação da terra na APA, na conjuntura atual, estão atrelados a diversos agentes produtores e transformadores do espaço. Sejam eles o poder público, principalmente os municipais e estadual, políticos e tomadores de decisões, sociedade civil, ONGs, sindicatos e organizações sociais, empresários, especuladores imobiliários, e mais recentemente, os turistas, que tecem nos núcleos urbanos e/ou rurais teias de relações entre sociedade $x$ natureza que podem se mostrar conflituosas.

Para melhor aferição das questões acima apontadas, se faz mister discutir alguns aspectos importantes das características dos meios urbano e rural das cidades e distritos que compõem a APA em análise, no que se refere a dinâmica populacional e a socioeconômica local e sub-regional.

AAPA da Serra de Baturité localiza-se, aproximadamente, a $80 \mathrm{~km}$ de Fortaleza via CE060, no Nordeste do Ceará em direção aos Sertões Centrais. Compreende uma Unidade de Conservação de Uso Direto, que foi instituída pelo Decreto-lei $n^{\circ} 20.956$ de 18/09/1990, pelo Governo do Estado, em uma área de 379 ha, para conservação de ambiente de serra úmida.

Pela proximidade da Região Metropolitana de Fortaleza, a APA recebe influência das cidades de tal região, sobretudo da capital Fortaleza. A economia fora historicamente baseada na agricultura, absorvendo a maior parte da População Economicamente Ativa, além do extrativismo. Atualmente o comércio e as impulsões dadas ao turismo, em razão da APA em estudo e de outros atrativos cênicos formados pela Serra da Aratanha e das cidades metropolitanas litorâneas, estão no topo da pirâmide econômica representada pelo Produto Interno Bruto (PIB) por setor de serviços, como será analisado em seguida.

Sobre a dinâmica população da APA, foram analisados os indicadores do IBGE com registros de 30 anos - 1970-2000. Nota-se que a população urbana era, em 2000, de $47.977(49,25 \%)$ habitantes e a população rural era de $49.427(50,74 \%)$ habitantes, a par de uma população total de 97.404 habitantes. Além de perceber que atualmente a população rural é superior a urbana em 1,45\%, a população total aferida para APA em 1991 era de 90.493 habitantes, que quando comparada com dados de 2000 implica em aumento da população total de $7,09 \%$ ou 6.911 habitantes. A Tabela 1 mostra um panorama geral desta evolução demográfica, exibindo os distritos considerados para este estudo.

Considerando tipologias diferenciadas no contexto da rede urbana global do Maciço, que influenciam em menor ou maior grau as formas de uso e ocupação do solo na APA, bem como vetores de desenvolvimento socioeconômico e de problemas ambientais emergentes, este trabalho destaca Ceará (2002, p. 22) na consideração de 2 (dois), entre 3 (três) núcleos distintos. Um terceiro núcleo, a priori, não detém representatividade sobre a Unidade de Conservação analisada, visto que os núcleos urbanos, hoje não interligados diretamente, de Barreira e Ocara (mesmo situados na Região Administrativa $n^{\circ} 08$ - Maciço de Baturité), não estabelecem relação interurbana forte com os dois subsistemas urbanos considerados em seguida.

Ceará (2002, p. 23) advoga que a esses dois núcleos, caberá, possivelmente, função econômica de suporte às atividades do setor primário e a agroindús- 
NASCIMENTO, F. R. et al. Diagnóstico socioeconômico da área de proteção ambiental...

TABELA 1 - EVOLUÇÃO DA POPULAÇÃO RESIDENTE NA REGIÃO DAAPA

\begin{tabular}{|c|c|c|c|c|c|c|c|}
\hline \multirow[t]{2}{*}{ Municipio } & \multirow[t]{2}{*}{ Situação } & \multicolumn{2}{|c|}{ Pop. residente } & \multirow[t]{2}{*}{ Municipio } & \multirow[t]{2}{*}{ Situação } & \multicolumn{2}{|c|}{ Pop. residente } \\
\hline & & 1991 & 2000 & & & 1991 & 2000 \\
\hline \multirow{3}{*}{ Aratuba - Sede } & Total & 10.578 & 12.359 & \multirow{3}{*}{ Pacoti-Sede } & Total & 4.791 & 5.207 \\
\hline & Urbana & 1.51 & 2.157 & & Urbana & 2.8 & 3.371 \\
\hline & Rural & 9.068 & 10.202 & & Rural & 1.991 & 1.836 \\
\hline \multirow{3}{*}{ Baturité - Sede } & Total & 23.973 & 26.777 & \multirow{3}{*}{ Colina - Pacoti } & Total & 2.632 & 2.36 \\
\hline & Urbana & 15.375 & 19.893 & & Urbana & 104 & 79 \\
\hline & Rural & 8.598 & 6.884 & & Rural & 2.528 & 2.281 \\
\hline \multirow{3}{*}{ Boa Vista - Baturité } & Total & 1.547 & 1.271 & \multirow{3}{*}{ Fátima - Pacoti } & Total & 1.026 & 1.455 \\
\hline & Urbana & 318 & 291 & & Urbana & 104 & 164 \\
\hline & Rural & 1.229 & 980 & & Rural & 922 & 1.291 \\
\hline \multirow{3}{*}{ São Sebastião - Baturité } & Total & 1.627 & 1.813 & \multirow{3}{*}{ Santa Ana - Pacoti } & Total & 1.651 & 1.907 \\
\hline & Urbana & 506 & 662 & & Urbana & 171 & 195 \\
\hline & Rural & 1.121 & 1.151 & & Rural & 1.48 & 1.712 \\
\hline \multirow{3}{*}{ Capistrano - Sede } & Total & 15.559 & 15.83 & \multirow{3}{*}{ Palmácia - Sede } & Total & 8.595 & 8.216 \\
\hline & Urbana & 4.459 & 5.252 & & Urbana & 3.391 & 3.97 \\
\hline & Rural & 11.1 & 10.578 & & Rural & 5.204 & 4.246 \\
\hline \multirow{3}{*}{ Guaramiranga - Sede } & Total & 2.429 & 2.589 & \multirow{3}{*}{ Gado - Palmácia } & Total & 1.205 & 1.257 \\
\hline & Urbana & 829 & 1.19 & & Urbana & 172 & 227 \\
\hline & Rural & 1.6 & 1.399 & & Rural & 1.033 & 1.03 \\
\hline \multirow{3}{*}{$\begin{array}{l}\text { Pernambuquinho - } \\
\text { Guaramiranga }\end{array}$} & Total & 2.864 & 3.125 & \multirow{3}{*}{$\begin{array}{l}\text { Gados dos Rodri- } \\
\text { gues - Palmácia }\end{array}$} & Total & 436 & 386 \\
\hline & Urbana & 743 & 1.14 & & Urbana & 162 & 220 \\
\hline & Rural & 2.121 & 1.985 & & Rural & 274 & 166 \\
\hline \multirow{3}{*}{ Mulungu - Sede } & Total & 7.842 & 8.897 & \multirow{3}{*}{ Guassi - Redenção } & Total & 3.738 & 3.955 \\
\hline & Urbana & 3.023 & 3.715 & & Urbana & 404 & 502 \\
\hline & Rural & 4.819 & 5.182 & & Rural & 3.334 & 3.453 \\
\hline
\end{tabular}

FONTE: IBGE (2000)

tria. Isso devido à sua posição geográfica no contexto geral do Maciço pela possível conexão com o corredor da ferrovia/rodovia CE 060, destacado logo abaixo, oportunizando alternativa de escoamento de produção para outras regiões do Estado.

Eis que, os dois conjuntos de núcleos urbanos de relevante interesse para uma análise da APA de Baturité são:

a) O "cordão de núcleos serranos" - formado pelas cidades de Aratuba, Mulungu, Guaramiranga, e Pacoti, se incluindo Palmácia, na hipótese de implantação da estrada Palmácia/ Pacoti. Este cordão em sua estrutura conta com a rodovia existente, com extensas matas bem conservadas. As áreas desmatadas estão ocupadas com segunda residência, fazendas não mais produtivas e, mais recentemente, complexos turísticos de pequeno porte, como pousadas, cujo uso mais intenso se dá nos finais de semana e feriados prolongados. São registrados também pequenos sítios voltados à produção de frutas e hortaliças, abrigando uma parcela da população rural do Maciço;

b) O "corredor potencial de urbanização" - definido pela CE060, atrelado ao corredor ferroviário de forte expressividade antigamente, interligando as cidades de Acarape, Redenção, Aracoiaba, Baturité (como núcleo central), Capistrano e Itapiúna. Considera-se que esse eixo, a partir da possibilidade de reabilitação do transporte ferroviário de passageiros e de carga, apresenta-se como potencial eixo de urbanização a ser desenvolvido.

De todas as cidades que têm ou mantêm influência com a APA em questão, sem dúvidas a cidade de Baturité se destaca pela sua infraestrutura urbana, 
NASCIMENTO, F. R. et al. Diagnóstico socioeconômico da área de proteção ambiental...

concentrando funções de serviços com lojas, bancos, sistema de transporte diversificado - incluindo aí a ferrovia -, e equipamentos sociais entre os mais bem estabelecidos de todo o maciço. $\mathrm{Na}$ cidade existem escolas públicas e privadas, um Campus Avançado da Universidade Estadual do Ceará, bem como clínica particular.

Recebe e irradia fluxos diários e constantes de pessoas, bens e mercadorias para a região do maciço, funcionando como cidade troncal para o desenvolvimento de atividades socioeconômicas sub-regionais.
A cidade de Baturité contribui como o maior contingente populacional na área de influência da APA homônima, e é também a principal cidade da região, com 26.777 habitantes, ou $27,49 \%$ da população local. Destes, 19.893 habitam o meio urbano e 6.884 habitantes habitam o meio rural. Esta população, ao longo de uma década cresceu 10,47\%, sempre com dominância da população urbana sobre a rural (Figura 2), com taxa de urbanização de $22,71 \%$.

De fato, seu núcleo urbano caracteriza-se pelo uso intensivo do solo com edificações, infraestruturas

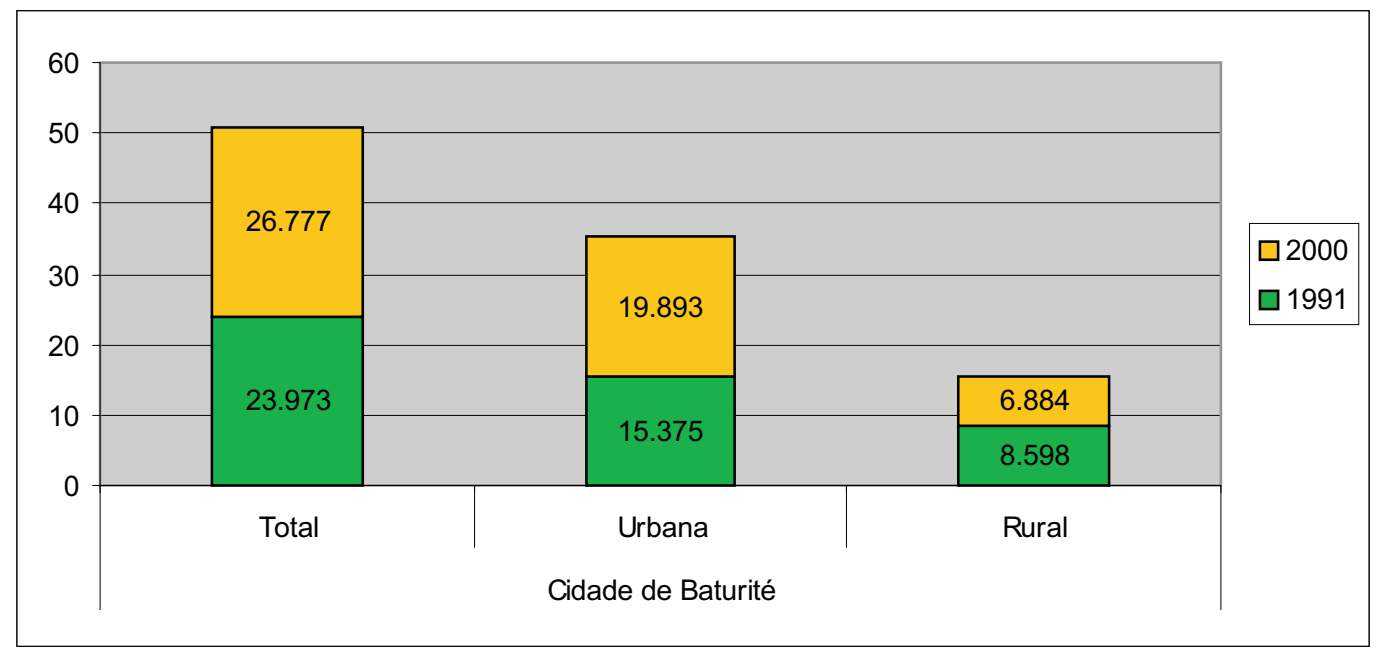

FIGURA 2 - DINÂMICA DEMOGRÁFICA DA POPULAÇÃO DA CIDADE DE BATURITÉ, 1991-2000

viárias e básicas, localizadas estrategicamente conforme as características do meio biofísico e vias de acesso. O crescimento da cidade é acompanhado por expansão da ocupação das áreas de baixo valor ou mesmo sem nenhum valor imobiliário, colaborando para a proliferação de núcleos de pobreza em relação ao já modesto centro municipal, denotando ocupação urbana concentrada e segregadora. A estrutura territorial da cidade relacionada à APA em destaque é resultado de um conjunto de processos e agentes organizadores do espaço. Desta feita, tem como principais agentes organizadores do espaço Estado, Prefeitura municipal, empresários do setor comercial e de serviços turístico e a sociedade civil organizada ou não, como já mencionado supracitado.

De todo modo, apresenta a estrutura urbana mais consolidada entre os núcleos urbanos averiguados, com tendência de concentração da expansão em direção a subida da Serra, bem como estrada que liga a CE060.
Onde os poderes governamentais do município e a dinâmica socioeconômica são impulsionadores do desenvolvimento da rede urbana. A cidade de Baturité detém a diversificação de serviços (rádio, telefonia, transportes etc.), espaços de lazer, estabelecimentos comerciais, instituições públicas e privadas, bem como a maior e melhor cobertura infraestrutural na região analisada, inclusive concentrando fortes bases do sistema financeiro entre todas as cidades analisadas, com os Bancos do Brasil e o Banco do Nordeste, por exemplo. Sendo que os demais são centros locais, que se caracterizam também como centros de comércio e serviços.

Revés, mas não menos importante para uma análise socioeconômica a que se pretende, dentre os distritos analisados que menos contribuem em quantitativo populacional na região da APA são os Distritos de Gado 1.257 habitantes e Gados dos Rodrigues 386, ambos em Palmácia (Figura 3).

O incremento do setor turístico é pujante na Serra 
NASCIMENTO, F. R. et al. Diagnóstico socioeconômico da área de proteção ambiental...

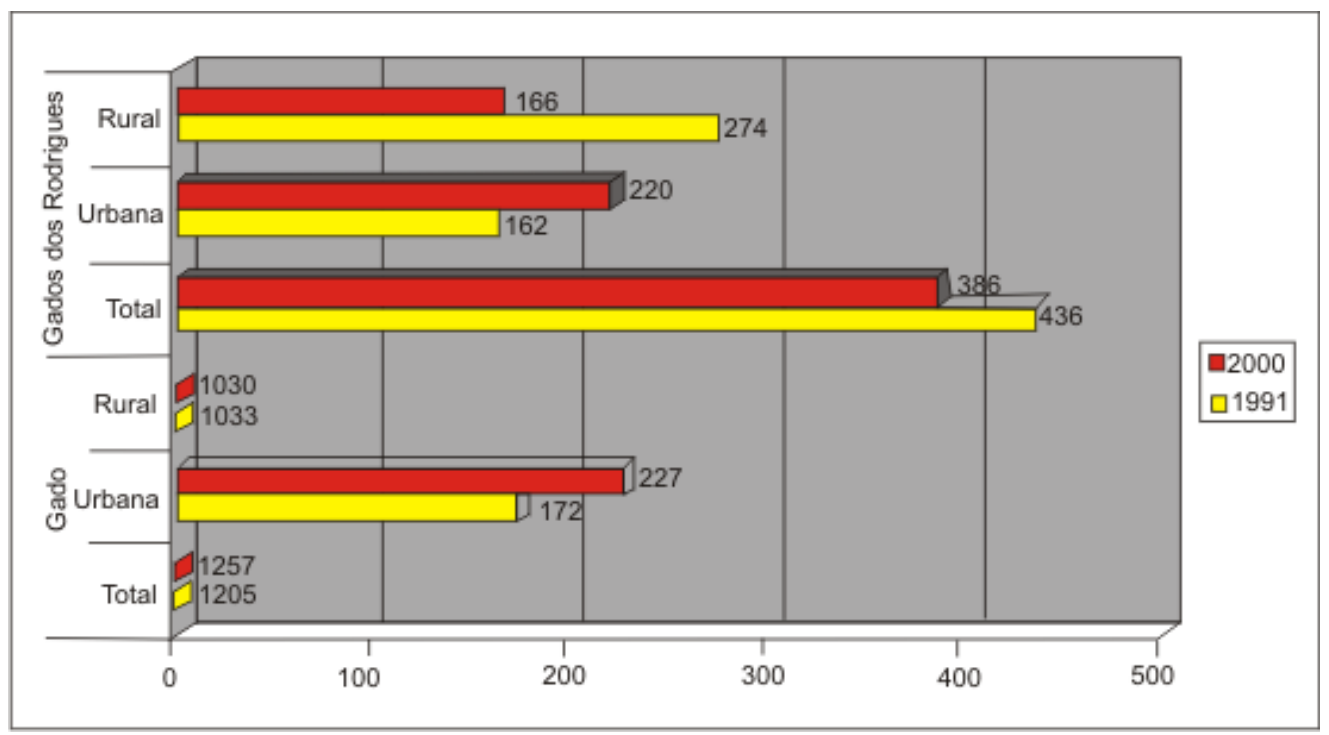

FIGURA 3 - DISTRITOS DE GADO E GADOS DOS RODRIGUES, DINÂMICA POPULACIONAL ENTRE 1991-2000

no perímetro da APA. Este tipo de serviço contribui para relacionar, de algum modo, a economia local e estadual incipiente com a macroeconomia do capital global. O modelo turístico de sol e praia, desenvolvido nas regiões litorâneas do Ceará é complementado por outras modalidades de turismo, como o ecoturismo e o turismo de aventura, proporcionados pelos ativos ambientais de serras úmidas, como a que resguarda a APA de Baturité. Como também, de modo independente, com a maioria dos turistas chegando ao Ceará via Fortaleza, demandam os atrativos serranos como demandas específicas, em razão de seus atrativos naturais, objetos e suportes turísticos, contribuindo para que a APA em questão seja uma das áreas mais visitadas de todo o Estado.

Em miúde, os equipamentos sociais merecem ser pontuados e destacados, como forma de mostra a disposição e condições dos setores de saúde e de educação.

O sistema educacional na região da APA da Serra de Baturité é formado por escolas públicas e privadas de Ensino Básico, Fundamental e Médio. Entre as escolas particulares e municipais Baturité novamente se destaca, com o maior número de estabelecimentos de ensino entre os municípios analisados. Por outro lado, o Município com menor número de estabelecimentos daqueles níveis de ensino é Aratuba, com apenas 8 escolas municipais, seguida por Palmácia e Aratuba, cada uma com 16 escolas municipais, 1 e 2 escolas particulares, respectivamente (Tabela 2).
TABELA 2 - ESTABELECIMENTOS DE ENSINO

\begin{tabular}{|c|c|c|c|c|c|}
\hline \multirow{2}{*}{ Municípios } & \multicolumn{5}{|c|}{ Estabelecimentos } \\
\cline { 2 - 6 } & TOTAL & Federal & Estadual & Municipal & Particular \\
\hline Aratuba & 8 & - & - & 8 & - \\
\hline Baturité & 62 & - & - & 45 & 17 \\
\hline Guaramiranga & 17 & - & - & 16 & 1 \\
\hline Mulungu & 20 & - & - & 18 & 2 \\
\hline Pacoti & 21 & - & - & 19 & 2 \\
\hline Palmácia & 18 & - & - & 16 & 2 \\
\hline Redenção & 34 & - & - & 31 & 3 \\
\hline
\end{tabular}

FONTE: Secretaria da Educação Básica do Estado do Ceará, Diretoria de Estatística - Sistema de Informações Educacionais.

Baturité se destaca pelo número de matrículas, número de docentes (562) e pelo fato haver registros do último senso de dados do Campus Avançado da Universidade Estadual do Ceará, hoje extinto. Ademais, os níveis de taxa de escolaridade da região estão no geral de médios a bons, como no caso de Guaramiranga, com taxa de escolarização no Ensino Fundamental de $97,88 \%$ e no Ensino Médio de 32,08\%. Contudo, não foram verificadas escolas de ensino profissionalizantes.

Entretanto, a qualidade do ensino exime meIhorias nas condições de infraestrutura, e em melhor remuneração e qualificação do quadro docente, principalmente na escola pública. Para se ter uma ideia, a repetência, evasão, abandono e a reprovação mostram indicadores preocupantes para região. Em Baturité, a 
NASCIMENTO, F. R. et al. Diagnóstico socioeconômico da área de proteção ambiental...

reprovação atinge cerca de $24,31 \%$ dos alunos, e o abandono $21,32 \%$ e a repetência $12,82 \%$.

A Educação Infantil (creches, pré-escolas e unidades de educação especial), o Ensino Fundamental $\left(1^{\mathrm{a}}\right.$ a $4^{\mathrm{a}}$ série e $5^{\mathrm{a}}$ a $8^{\mathrm{a}}$ série) e o Ensino Médio, foram avaliados em termos de número de matrículas. Desta feita foi observado o seguinte:

- Ensino Infantil: O menor número de matrículas foi verificado em Mulungu (401) e Palmácia (451);

- Ensino Fundamental: o maior número de matrículas está entre a $1^{\mathrm{a}}$ e a $4^{\mathrm{a}}$ série e anos iniciais, com destaque para Baturité, com 3.939 matrículas e para a cidade serrana de Pacoti, $3^{\circ}$ lugar em número de matrícula, com 1.582.

- Ensino Médio: Baturité lidera sobre os demais municípios, com 1.555 matrículas. Isso representa 3,1 vezes o número da média de matrículas considerando os outros municípios analisados. Redenção apresentou, em 2000, 1.460 - ficando em segundo lugar -; Guaramiranga detinha apenas 225 matrículas e Mulungu 333 matrículas.

Estes dados podem ser melhor observados na Tabela 3, a qual apresenta as matrículas iniciais nas escolas Municipais Estaduais e Particulares conforme os níveis de ensino para os Municípios analisados.

Considerando-se a obrigatoriedade do atendimento ao Ensino Fundamental, prevista na Constituição Federal, e a importância deste para o desenvolvimento do cidadão, projeta-se a necessidade de melhoras urgentes nesse setor tão importante para ambos os municípios. Seria importante destacar, como considera os Parâmetros Curriculares Nacionais, disciplinas e conteúdos que valorizem a questão ambiental e a relação sociedade versus natureza, tomando, por exemplo, a APA da Serra de Baturité.

As condições de vida da população dos municípios considerados é reflexo da estruturação de sua base produtiva e da infraestrutura em saúde pública, educação, saneamento básico, habitação e outros serviços sociais. A ausência de saneamento básico, além do mau uso dos recursos hídricos e consequente degradação do meio ambiente, influencia, diretamente, as condições de saúde da população, especialmente das crianças em faixas etárias mais baixas. Quanto piores as condições de saneamento, maiores são os riscos de mortalidade infantil, de incidência de doenças infecto-contagiosas e outros problemas de saúde.

No que se refere à saúde, os Municípios em questão adotam o Sistema Único de Saúde (SUS) e incorporam o modelo proposto pelo Governo do Estado para a criação do Programa de Saúde da Família (PSF). Os municípios ofertam atenção primária e secundária que permitem o acompanhamento dos principais agravos à saúde, em termos de atendimento em nível ambulatorial. A Assistência Básica atua via Programa de Saúde da Família (PSF) e a Assistência Secundária, a nível ambulatorial e/ou hospitalar dependendo da complexidade do quadro, através do Sistema Único de Saúde (SUS).

O sistema de saúde da região da APA comporta 119 unidades de saúde. Estão consideradas aí: Postos e centros de saúde; consultórios médicos/odontológicos; policlínicas, unidades móveis e mistas, bem como de vigilância sanitária, unidades do PSF e outros. Assim, para cada município analisado existe um (01) hospital e a seguinte quantidade de unidades de saúde: Redenção 24; Baturité 29; Pacoti 16; Capistrano 14; Aratuba 11; Guaramiranga 6; Munlugu 7 e Palmácia 12.

Entretanto, os casos de maior gravidade são encaminhados para o Hospital Regional de Aracoiaba, e quando necessário para a capital Fortaleza.

Os profissionais de saúde ligados ao SUS se concentram em maior quantidade em Baturité (223) e o Município menos assistido é Aratuba, com apenas 82 profissionais. Os Agentes comunitários de saúde são os profissionais mais comuns na região, com 253 trabalhadores, seguidos de perto por aqueles que possuem nível médio, os quais somam 248 trabalhadores. Palmácia e Baturité detém o maior número de médicos, cada uma com 50 profissionais, o que representa $45,87 \%$ de um total de 278 médicos. Revés, apenas $9,4 \%$ destes profissionais se concentram em Mulungu, ou 66 médicos, como mostra a Tabela 4.

Os 253 agentes comunitários que fazem parte do 
NASCIMENTO, F. R. et al. Diagnóstico socioeconômico da área de proteção ambiental...

TABELA 3 - MATRÍCULA INICIAL POR NÍVEL DE ENSINO NA REGIÃO DA APA DA SERRA DE BATURITÉ

\begin{tabular}{|c|c|c|c|c|c|c|c|c|c|c|c|c|c|c|}
\hline & & \multirow[b]{2}{*}{ Creche } & \multirow[b]{2}{*}{$\begin{array}{l}\text { Pré- } \\
\text { Escola }\end{array}$} & \multicolumn{4}{|c|}{ Ensino Fundamental (Regular) } & \multirow[b]{2}{*}{$\begin{array}{c}\text { Ensino } \\
\text { Médio } \\
\text { (Regular) }\end{array}$} & \multicolumn{2}{|c|}{$\begin{array}{l}\text { Educação } \\
\text { Especial }\end{array}$} & \multicolumn{2}{|c|}{$\begin{array}{l}\text { Ed. de Jovens e } \\
\text { Adult (presencial) }\end{array}$} & \multicolumn{2}{|c|}{$\begin{array}{l}\text { EJA (semi- } \\
\text { presencial) }\end{array}$} \\
\hline & & & & $\begin{array}{c}\text { Educação } \\
\text { Especial } \\
\text { (Incluídos) }\end{array}$ & Total & $\begin{array}{c}1^{\mathrm{a}} \text { a } 4^{\mathrm{a}} \\
\text { série e } \\
\text { Anos } \\
\text { Iniciais }\end{array}$ & $\begin{array}{c}5^{\mathrm{a}} \text { a } 8^{\mathrm{a}} \\
\text { série e } \\
\text { Anos } \\
\text { Finais }\end{array}$ & & Total & $\begin{array}{l}\text { Funda- } \\
\text { mental }\end{array}$ & Total & $\begin{array}{l}\text { Funda- } \\
\text { mental }\end{array}$ & Total & $\begin{array}{l}\text { Funda- } \\
\text { mental }\end{array}$ \\
\hline \multirow{3}{*}{ ARATUBA } & Total & 162 & 518 & 26 & 3.160 & 1.765 & 1.395 & 631 & 0 & 0 & 294 & 197 & 0 & 0 \\
\hline & Estadual & 0 & 18 & 2 & 45 & 45 & 0 & 631 & 0 & 0 & 149 & 52 & 0 & 0 \\
\hline & Municipal & 162 & 500 & 24 & 3.115 & 1.720 & 1.395 & 0 & 0 & 0 & 145 & 145 & 0 & 0 \\
\hline \multirow{4}{*}{ BATURITÉ } & Total & 709 & 1.539 & 12 & 6.916 & 3.939 & 2.977 & 1.555 & 41 & 23 & 1.495 & 1.182 & 612 & 210 \\
\hline & Estadual & 0 & 0 & 1 & 857 & 34 & 823 & 1.373 & 0 & 0 & 1.006 & 693 & 612 & 210 \\
\hline & Municipal & 510 & 890 & 8 & 4.803 & 3.193 & 1.610 & 0 & 41 & 23 & 444 & 444 & 0 & 0 \\
\hline & Privada & 199 & 649 & 3 & 1.256 & 712 & 544 & 182 & 0 & 0 & 45 & 45 & 0 & 0 \\
\hline \multirow{4}{*}{ GUARAMIRANGA } & Total & 0 & 353 & 7 & 1.245 & 723 & 522 & 225 & 16 & 2 & 60 & 60 & 0 & 0 \\
\hline & Estadual & 0 & 0 & 0 & 88 & 0 & 88 & 225 & 0 & 0 & 44 & 44 & 0 & 0 \\
\hline & Municipal & 0 & 334 & 7 & 1.104 & 670 & 434 & 0 & 16 & 2 & 16 & 16 & 0 & 0 \\
\hline & Privada & 0 & 19 & 0 & 53 & 53 & 0 & 0 & 0 & 0 & 0 & 0 & 0 & 0 \\
\hline \multirow{4}{*}{ MULUNGU } & Total & 159 & 401 & 66 & 2.015 & 1.165 & 850 & 333 & 0 & 0 & 304 & 228 & 0 & 0 \\
\hline & Estadual & 0 & 0 & 0 & 0 & 0 & 0 & 333 & 0 & 0 & 76 & 0 & 0 & 0 \\
\hline & Municipal & 149 & 319 & 65 & 1.898 & 1.067 & 831 & 0 & 0 & 0 & 228 & 228 & 0 & 0 \\
\hline & Privada & 10 & 82 & 1 & 117 & 98 & 19 & 0 & 0 & 0 & 0 & 0 & 0 & 0 \\
\hline \multirow{4}{*}{ PACOTI } & Total & 275 & 451 & 122 & 2.575 & 1.582 & 993 & 467 & 8 & 8 & 497 & 305 & 0 & 0 \\
\hline & Estadual & 0 & 0 & 1 & 106 & 0 & 106 & 467 & 0 & 0 & 256 & 64 & 0 & 0 \\
\hline & Municipal & 275 & 314 & 120 & 2.331 & 1.444 & 887 & 0 & 8 & 8 & 241 & 241 & 0 & 0 \\
\hline & Privada & 0 & 137 & 1 & 138 & 138 & 0 & 0 & 0 & 0 & 0 & 0 & 0 & 0 \\
\hline \multirow{4}{*}{ PALMÁCIA } & Total & 50 & 423 & 103 & 2.262 & 1.204 & 1.058 & 460 & 0 & 0 & 254 & 180 & 0 & 0 \\
\hline & Estadual & 0 & 0 & 0 & 137 & 0 & 137 & 460 & 0 & 0 & 74 & 0 & 0 & 0 \\
\hline & Municipal & 50 & 391 & 101 & 1.996 & 1.099 & 897 & 0 & 0 & 0 & 180 & 180 & 0 & 0 \\
\hline & Privada & 0 & 32 & 2 & 129 & 105 & 24 & 0 & 0 & 0 & 0 & 0 & 0 & 0 \\
\hline \multirow{4}{*}{ REDENÇÃO } & Total & 283 & 1.045 & 40 & 6.059 & 3.470 & 2.589 & 1.460 & 0 & 0 & 1.026 & 703 & 0 & 0 \\
\hline & Estadual & 0 & 0 & 0 & 248 & 0 & 24 & 1.365 & 0 & 0 & 357 & 34 & 0 & 0 \\
\hline & Municipal & 252 & 916 & 38 & 5.310 & 3.181 & 2.129 & 0 & 0 & 0 & 669 & 669 & 0 & 0 \\
\hline & Privada & 31 & 129 & 2 & 501 & 289 & 212 & 95 & 0 & 0 & 0 & 0 & 0 & 0 \\
\hline
\end{tabular}

FONTE: Censo Escolar INEP 2003.

TABELA 4 - PROFISSIONAIS DE SAÚDE LIGADOS AO SUS

\begin{tabular}{|c|c|c|c|c|c|c|c|}
\hline \multirow[b]{2}{*}{ Municípios } & \multicolumn{7}{|c|}{ Profissionais de Saúde } \\
\hline & Total & Médicos & Dentistas & Enfermeiros & $\begin{array}{l}\text { Outros profis- } \\
\text { sionais de saúde/ } \\
\text { nível superior }\end{array}$ & $\begin{array}{c}\text { Agentes comunitários } \\
\text { de saúde }\end{array}$ & $\begin{array}{l}\text { Profissionais de } \\
\text { saúde/ nível médio }\end{array}$ \\
\hline Aratuba & 82 & 24 & 3 & 7 & 7 & 27 & 14 \\
\hline Baturité & 223 & 50 & 9 & 9 & 16 & 51 & 88 \\
\hline Guaramiranga & 68 & 14 & 5 & 9 & 8 & 20 & 12 \\
\hline Mulungu & 66 & 11 & 2 & 7 & 3 & 19 & 24 \\
\hline Pacoti & 108 & 20 & 5 & 8 & 4 & 28 & 43 \\
\hline Palmácia & 136 & 50 & 6 & 13 & 2 & 32 & 33 \\
\hline Redenção & 278 & 117 & 16 & 18 & 17 & 76 & 34 \\
\hline
\end{tabular}


NASCIMENTO, F. R. et al. Diagnóstico socioeconômico da área de proteção ambiental...

Programa Agentes de Saúde acompanharam 23.277 famílias, perfazendo um total de 92.215 pessoas assistidas com maior e menor atuação em Baturité e Mulungu (Tabela 5).

TABELA 5 - AGENTES DE SAÚDE, FAMÍLIAS ACOMPANHADAS E POPULAÇÃO ASSISTIDA, 2000

\begin{tabular}{|c|c|c|c|}
\hline Municípios & $\begin{array}{c}\text { Agentes } \\
\text { de Saúde }\end{array}$ & $\begin{array}{c}\text { Famílias } \\
\text { Acompanhadas }\end{array}$ & $\begin{array}{c}\text { População } \\
\text { Assistida }\end{array}$ \\
\hline Aratuba & 27 & 3.004 & 12.424 \\
\hline Baturité & 51 & 6.717 & 26.498 \\
\hline Guaramiranga & 20 & 1.405 & 6.048 \\
\hline Mulungu & 19 & 1.980 & 8.066 \\
\hline Pacoti & 28 & 3.169 & 12.197 \\
\hline Palmácia & 32 & 2.597 & 9.510 \\
\hline Redenção & 76 & 4.405 & 17.472 \\
\hline
\end{tabular}

FONTE: Secretaria Estadual da Saúde, Sistema de Informações do Programa Agentes de Saúde.

Nota: Agentes Comunitários de Saúde cadastrados e em atividade.

Na Tabela 6 pode-se visualizar que, nos Municípios em apreço, o Programa de Saúde da Família contava, em 2000, com 20 equipes, cobrindo em média cerca de $91 \%$ da população regional, o equivalente a 103.531 da população considerada.

A par da caracterização geral dos núcleos urbanos e rurais da região da APA da Serra de Baturité e de alguns aspectos importantes sobre sua condição socioeconômica, foram destacados, em seguida, a estrutura etária e o panorama do mercado de trabalho.

TABELA 6 - POPULAÇÃO ESTIMADA E PERCENTUAL DE COBERTURA DO PSF, 2000.

\begin{tabular}{|c|c|c|}
\hline Municípios & No de Equipes & \% de Cobertura \\
\hline Aratuba & 5 & 88,1 \\
\hline Baturité & - & 85,9 \\
\hline Guaramiranga & 2 & 102,8 \\
\hline Mulungu & - & 86,5 \\
\hline Pacoti & 4 & 108,3 \\
\hline Palmácia & 3 & 98 \\
\hline Redenção & 6 & 67,5 \\
\hline
\end{tabular}

FONTE: Secretaria Estadual da Saúde, Assessoria de Planejamento e Coordenação.

\section{ESTRUTURA ETÁRIA E O PANORAMA DO MERCADO DE TRABALHO}

A distribuição etária da população na região da APA da Serra de Baturité foi avaliada com base nos dados do IBGE de 2000 , os quais agrupam a população em 7 faixas etárias. A saber: 5 a 9 anos; 10 a 19 anos; 20 a 29 anos; 30 a 39 anos; 40 a 49 anos; 50 a 59 anos; 60 anos ou mais.

Observa-se a população em sua ordem de dominância de grupos modais, a faixa etária de 10 a 19 anos, seguida de perto pela faixa que comporta pessoas de 20 a 29 anos (Tabela 7). Deste modo, a estrutura etária mostra que a taxa de fecundidade vem reduzindo atrelada a queda de ritmo do crescimento populacional. A principal tendência atual mostra-se na predominância da parcela da população em idade ativa ou população alienável como força de trabalho (10 a 19 anos e 20 a 29 anos). Isto se reflete na redução progressiva da razão de dependência, e esta define o peso das faixas etárias não produtivas sobre as faixas etárias que correspondem à força de trabalho ativa.

As repercussões da atual estrutura etária da população sobre o mercado de trabalho fazem-se sentir através da pressão de procura por trabalho. A característica marcante dessa procura por trabalho é ser uma busca pelo primeiro emprego, típica de uma força de trabalho jovem e sem experiência no mercado. Essa pressão de procura por trabalho é o que se denomina usualmente de desemprego não cessante.

Essa população jovem constitui uma fonte de pressão adicional e crescente ao longo do tempo sobre o mercado de trabalho local, inclusive provocando movimentos pendulares com os trabalhadores indo ter com o mercado de trabalho em Fortaleza, ou de outras cidades do interior do Ceará ou mesmo fora do Estado e Região Nordeste.

TABELA 7 - GRUPOS MODAIS PREDOMINANTES, POR FAIXAS ETÁRIAS

\begin{tabular}{|c|c|c|}
\hline \multirow{2}{*}{ Municípios } & \multicolumn{2}{|c|}{ Faixas etárias - percentagens } \\
\cline { 2 - 3 } & 10 a 19 anos & 20 a 29 anos \\
\hline Pacoti (Sede) & 27 & 17 \\
\hline Colina & 28 & 15 \\
\hline Fátima & 24 & 16 \\
\hline Capistrano & 27 & 17 \\
\hline Palmácia (Sede) & 26 & 17 \\
\hline Gado & 28 & 15 \\
\hline Gados dos Rodrigues & 23 & 21 \\
\hline Redenção (Guassi) & 28 & 15 \\
\hline Baturité (Sede) & 25 & 18 \\
\hline Boa Vista & 27 & 17 \\
\hline São Sebastião & 27 & 16 \\
\hline Aratuba (Sede) & 28 & 16 \\
\hline Guaramiranga (Sede) & 27 & 20 \\
\hline Pernambuquinho & 25 & 15 \\
\hline Média total de dominância & 26,42 & 16,78 \\
\hline
\end{tabular}


NASCIMENTO, F. R. et al. Diagnóstico socioeconômico da área de proteção ambiental...

Na medida em que as atividades tradicionais de bases agroextrativistas sofrem processo de dissolução, as relações de produção não tipicamente capitalistas ou pelo menos com divisão social do trabalho com base familiar ou comunitária/coletiva vão perdendo lugar para as relações mercantis, tanto no campo como no meio urbano. Deste modo, seja no âmbito das relações de produção, seja no âmbito de reprodução social e do consumo, estão ocorrendo transformações substanciais na sociedade local.

Quando se observa a distribuição etária da população, segundo os critérios de dependência e atividade econômica da população, constata-se que a razão de dependência vem caindo nos dois Municípios. O quociente entre "população dependente" (pessoas com 15 ou 60 anos ou mais de idade), e "população ativa" (população com idade entre 15 e 64 anos), no geral permanece alto. Nesse caso temos o exemplo de Aratuba, Guaramiranga e Palmácia, com 93,98; 86,24 e 87,89 .

Esse comportamento pode ser atribuído à diminuição dos grupos etários mais jovens, com menos de dezenove anos de idade. Por outro lado, os grupos etários que compõem a População em Idade Ativa (PIA) apresentaram considerável ampliação nos últimos dez anos.

A População Economicamente Ativa - PEA, que engloba pessoas de 10 a 65 anos de idade, foram classificadas como ocupadas ou desocupadas na semana de referência da pesquisa do IBGE. No entanto, para análise dos Municípios foi considerada a PEA por setor de domicílio (urbano e rural) e ocupada. Observa-se, que em função de uma rápida urbanização de alguns municípios, como em Baturité, há crescimento expressivo da PEA. Principalmente, do contingente atrelado ao setor de serviços, tendo como consequência uma pressão adicional sobre a demanda por bens e serviços públicos.

A estrutura do mercado de trabalho revela um panorama no qual o contingente de pessoas em idade ativa (dez anos ou mais), que estão em atividade (economicamente ativas) se distribui em ocupadas e desocupadas. O enfoque para a análise deste estudo foi o grupo da PEA ocupada para os Municípios. Notase um total de 43.323 pessoas economicamente ativas ocupadas, e que as 4.302 compõem a PEA desocupada (Tabela 8).
TABELA 8 - POPULAÇÃO ECONOMICAMENTE ATIVA

\begin{tabular}{|c|c|c|c|c|}
\hline Municípios & $\begin{array}{c}\text { Pessoas de } \\
\text { 10 anos ou } \\
\text { mais de idade }\end{array}$ & $\begin{array}{c}\text { Pessoas } \\
\text { economica- } \\
\text { mente ativas }\end{array}$ & Ocupadas & Desocupadas \\
\hline Aratuba & 9.115 & 4.630 & 4.190 & 440 \\
\hline Baturité & 23.135 & 11.502 & 10.200 & 1.302 \\
\hline Capistrano & 12.100 & 4.972 & 4.462 & 510 \\
\hline Guaramiranga & 4.277 & 2.428 & 2.178 & 250 \\
\hline Mulungu & 6.864 & 3.232 & 3.029 & 203 \\
\hline Pacoti & 8.332 & 3.792 & 3.576 & 216 \\
\hline Palmácia & 7.605 & 3.469 & 2.989 & 480 \\
\hline Redenção & 19.292 & 9.298 & 8.397 & 901 \\
\hline
\end{tabular}

FONTE: IBGE (2000)

O município como menor PEA é Guaramiranga, com 4.277 pessoas, sendo que 2.428 destas foram classificadas, segundo o IBGE (2000), como ativas e a PEA ocupada 2.178 pessoas, ou $50,9 \%$ do total. Baturité detém o maior contingente de PEA, com 23.135 pessoas com 10 anos ou mais de idade, o que representa $25,50 \%$ de toda a PEA regional. Destes, 11.502 representam a PEA ativa, 10.200 a PEA ocupada e 1.302 a desocupada (Figura 4).

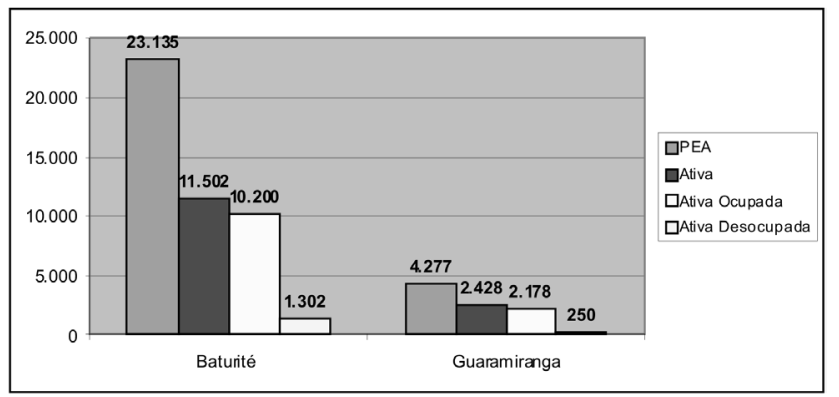

FIGURA 4 - POPULAÇÃO ECONOMICAMENTE ATIVA, OCUPADA E DESOCUPADA

A estrutura ocupacional permite revelar o padrão predominante nas relações de trabalho nos Municípios. Do contingente de população economicamente ativa analisada, a parcela ocupada por categoria de emprego apresenta como característica principal a predominância de ocupações assalariadas sem registro em carteira ou de trabalho autônomo, com total de 13.569 
NASCIMENTO, F. R. et al. Diagnóstico socioeconômico da área de proteção ambiental...

trabalhadores. Os que têm carteira assinada somam 5.860 trabalhadores. Isto representa $37,76 \%$ e $15,01 \%$ do total de trabalhadores, sejam os domésticos ou demais trabalhadores assalariados. Os trabalhados não cobertos pelo Código de Leis Trabalhistas, comumente, estão submetidos a relações de trabalho precárias, que podem ser insalubres e sobre-exploradora da mão-deobra (Tabela 9).

TABELA 9 - PESSOAS OCUPADAS, POR SUBGRUPO DE EMPREGO NO TRABALHO PRINCIPAL (2000)

\begin{tabular}{|c|c|c|c|c|c|c|c|c|}
\hline \multirow{4}{*}{ Municípios } & & \multicolumn{7}{|c|}{ Subgrupo do emprego assalariado no trabalho principal } \\
\hline & \multirow{3}{*}{ Total } & \multicolumn{3}{|c|}{ Trabalhadores domésticos } & \multirow[b]{3}{*}{ Total } & \multicolumn{3}{|c|}{ Demais Assalariados } \\
\hline & & \multirow[b]{2}{*}{ Total } & \multicolumn{2}{|c|}{$\begin{array}{l}\text { Categoria do emprego } \\
\text { no trabalho principal }\end{array}$} & & \multicolumn{3}{|c|}{ Categoria do emprego no trabalho principal } \\
\hline & & & $\begin{array}{l}\text { Com carteira } \\
\text { de trabalho } \\
\text { assinada }\end{array}$ & $\begin{array}{l}\text { Sem carteira } \\
\text { de trabalho } \\
\text { assinada }\end{array}$ & & $\begin{array}{l}\text { Com carteira } \\
\text { de trabalho } \\
\text { assinada }\end{array}$ & $\begin{array}{l}\text { Militares e fun- } \\
\text { cionários públicos } \\
\text { estatutários }\end{array}$ & $\begin{array}{l}\text { Outros sem carteira } \\
\text { de trabalho assinada }\end{array}$ \\
\hline Aratuba & 1.695 & 115 & - & 115 & 1.580 & 233 & 334 & 1.014 \\
\hline Baturité & 5.548 & 730 & 100 & 630 & 4.818 & 1.662 & 369 & 2.788 \\
\hline Capistrano & 1.973 & 286 & 23 & 263 & 1.687 & 692 & 95 & 900 \\
\hline Guaramiranga & 1.720 & 386 & 45 & 341 & 1.334 & 205 & 190 & 938 \\
\hline Mulungu & 1.679 & 230 & 27 & 203 & 1.449 & 318 & 70 & 1.061 \\
\hline Pacoti & 2.107 & 211 & 10 & 201 & 1.896 & 441 & 112 & 1.343 \\
\hline Palmácia & 1.567 & 243 & 11 & 232 & 1.324 & 461 & 130 & 734 \\
\hline Redenção & 4.720 & 789 & 37 & 752 & 3.931 & 1.595 & 282 & 2.054 \\
\hline
\end{tabular}

Fonte: IBGE

\section{ÚLTIMAS OBSERVAÇÕES}

Como foi apontado, o território da APA do Maciço de Baturité é formado ou está contíguo a um conjunto de 7 cidades ou sedes municipais, e 9 distritos conformando seu perímetro, a saber: Sedes dos Municípios de Aratuba, Capistrano, Mulungu; e Sedes e Distritos de Pacoti (Colina, Fátima e Santa Ana), Guaramiranga (Sede e Pernambuquinho), Baturité (Sede, Boa Vista, São Sebastião), Palmácia (Sede, Gado e Gados dos Rodrigues) e Redenção (Guassi).

Do ponto de vista de uma história econômica o Maciço de Baturité se enquadra no vetor de colonização e civilização das serras úmidas, a despeito de outras serras no Ceará (Maranguape, Serra das Matas, Aratanha, Uruburetama, Meruoca, Uruoca e Ibiapaba), com características específicas e com similaridades à ocupação de vales úmidos e férteis no sul do Ceará. Considerado o aporte de recursos naturais o modo de viver e de trabalhar reconhecíveis no contexto geral da civilização cearense etc., identificam-se tipologias de ocupação e exploração do solo e de povoamento bem específicos e diferenciados, com predominância de minifúndio, sítios e chácaras, ao se comparar com as lógicas das grandes propriedades rurais dos sertões semiáridos. Todavia, o tamanho do imóvel rural na serra em números não mostra essência dos conflitos que ocorrem na APA.

Tomando como base ciclos econômicos de desenvolvimento regional onde se insere a APA da Serra de Baturité, pode-se afirmar que conforme cada conjuntura econômica, com seus ciclos produtivos respectivos a produção do espaço, no campo ou cidade, foram (e são) produzidos ao longo da história novos processos de territorialização, a partir das lógicas de desenvolvimento regionais.

Atualmente toda a APA é polarizada pela Região Metropolitana de Fortaleza com a qual mantém relações políticas, econômicas e sociais. A economia ainda tem como base o setor primário e, principalmente, o terciário, os quais absorvem a maior parte da População Economicamente Ativa. Ligado ao terceiro setor da economia, o turismo tem se destacado na última década como atividade que vem incrementando as finanças da 
NASCIMENTO, F. R. et al. Diagnóstico socioeconômico da área de proteção ambiental...

APA nas cidades de Guaramiranga e Pacoti, porém, paradoxalmente é uma atividade que causa impactos ambientais negativos e com pífios incrementos no que tange a produção e distribuição de riquezas.

Nos últimos anos a tônica tem sido o incremento do setor imobiliário ligado à construção civil, de onde derivam sérios problemas ambientais e territoriais com diversos conflitos entre empresários imobiliários e população local, turistas e veranistas e população local, por exemplo.

Hoje, em prol do crescimento econômico regional, o poder público vem incorporando, vis-à-vis o território legal da APA de Baturité, em particular, e a região do Maciço como um todo, à economia estadual, em especial à metropolitana, a partir da viabilização de vias de acessos (CE 060, CE 356 e CE 115, estrada de Maranguape). Conforme projetado pelo Governo do Estado do Ceará, a exploração da beleza cênica com consolidação da rede hoteleira, regulação normativa e fiscal da APA, bem como elaboração de Plano de Manejo (em 2006), e agora de um ZEE - Zoneamento Ecológico Econômico -, vem consolidando essa incorporação.

No momento em que a SEMACE busca obter ferramentas técnicas para fundamentar o controle e monitoramento da qualidade ambiental da serra, há de se considerar alguns pressupostos e requisitos básicos. É fundamental a elaboração de um plano de manejo que venha a subsidiar uma perspectiva de ordenamento territorial, em face de políticas públicas de meio ambiente e desenvolvimento.

Deste modo, com base em informações do diagnóstico socioeconômico aqui trabalhadas, há necessidade premente de: executar políticas públicas orientadas à conservação do patrimônio natural, incentivando-se a sua regulamentação; criar mecanismos de gestão e manutenção desses espaços que abrigam o patrimônio ecológico do enclave úmido; reverter a expansão desordenada do crescimento urbano e de loteamentos em áreas de habitabilidade precária e sem obediência aos requisitos mínimos preconizados pela Legislação; investimento nos setores básicos da economia, com fortalecimento da qualificação técnica, profissional e educacional da população local. E, como fim comum o trilhar de uma perspectiva de convívio com menos conflito, porque não harmônico, nas relações da sociedade com a natureza.

\section{REFERÊNCIAS}

CEARÁ. Superintendência Estadual do Meio Ambiente. Zoneamento Ambiental da APA da Serra de Baturité. Diagnóstico e Diretrizes. Fortaleza: SEMACE, 1991. p. 3163.

- Zoneamento Ambiental da Serra de Baturité. Diagnóstico e Diretrizes. Fortaleza: SEMACE, 1991.

Plano de desenvolvimento regional do maciço de Baturité. Consórcio Faustino Nilo-Esplano Plano. 2002. 44p.

GIRÃO, Raimundo. Evolução histórica do Ceará. Fortaleza: BNB/ETENE, 1985, p. 50-185.

IBAMA/UECE. Gestão Biorregional do Maciço de Baturité (CE). Fortaleza, 2001. 183p.

IBGE. Economia. Disponível em: <http://www.ibge.gov.br>, Acesso em: 29/03/2009.

IPECE. Anuário Estatístico do Ceará. Disponível em: <http:// www2.ipece.ce.gov.br/publicacoes/anuario/anuario2007>. Acesso em: 25/03/2009.

PDR. Caracterização do Maciço de Baturité - Carências e potencialidades. Consórcio Faustino Nilo-Esplano Plano, 2002.

SOUZA, Marcos J. N de. et al. Diagnóstico e macrozoneamento do Ceará. Diagnóstico socioeconômico. FCPC/SEMANCE, 1998. p. 1-90. 
